\title{
Biomineralized hybrid nanoparticles for imaging and therapy of cancers
}

\author{
Kyung Hyun Min ${ }^{1}$, Hong Jae Lee ${ }^{1}$, Sang Cheon Lee ${ }^{1}$, Kyeongsoon Park ${ }^{2}$ \\ ${ }^{1}$ Department of Maxillofacial Biomedical Engineering and Institute of Oral Biology, School of Dentistry, Kyung Hee University, Seoul 02447, \\ Republic of Korea; ${ }^{2}$ Department of Systems Biotechnology, Chung-Ang University, Anseong, Gyeonggi 17546, Republic of Korea
}

Correspondence to: Sang Cheon Lee, PhD. Department of Maxillofacial Biomedical Engineering and Institute of Oral Biology, School of Dentistry, Kyung Hee University, Seoul 02447, Republic of Korea. Email: schlee@khu.ac.kr; Kyeongsoon Park, PhD. Department of Systems Biotechnology, Chung-Ang University, Anseong, Gyeonggi, 17546, Korea. Email: kspark1223@cau.ac.kr.

\begin{abstract}
In this review, we describe the research trends of hybrid nanocarriers developed based on a biomimetic mineralization process, and their recent applications in imaging and therapy of cancers. Organic-inorganic hybrid nanostructures formed by diverse biomimetic mineralization approaches are briefly reviewed, and particularly, the biomedical applications of these hybrid nanocarriers for the diagnosis and therapy of cancers are discussed. Biomineralization is an important process in which living organisms produce biominerals, such as calcium phosphate $(\mathrm{CaP})$, calcium carbonate $\left(\mathrm{CaCO}_{3}\right)$, and silica $\left.(\mathrm{SiO})_{2}\right)$, to strengthen their tissues, as found in the formation of bone and teeth. Introducing the artificial biomimetic mineralization process to nanobiotechnology has inspired researchers to develop smart stimuli-responsive nanoparticles for multiple purposes, such as improved therapeutic activity and activatable imaging of cancers.
\end{abstract}

Keywords: Biominerals; mineralization; organic-inorganic hybrid nanoparticles; cancer; therapy; imaging; theranostics

Submitted Aug 02, 2018. Accepted for publication Aug 10, 2018.

doi: 10.21037/qims.2018.08.04

View this article at: http://dx.doi.org/10.21037/qims.2018.08.04

\section{Introduction}

Recent advances in the field of nanomaterials exhibiting excellent therapeutic activity have attracted significant attention for the extended applications of novel drug delivery systems (1-3). For a successful treatment, it is recognized that nanodelivery systems should satisfy a number of prerequisites (4). In particular, the research needs to improve the biosafety, bioavailability, and biostability of nanocarriers are one of the main issues for the successful delivery of drugs, genes, proteins, and imaging agents to targeted disease sites. To meet the above requirements, various smart nanocarriers such as liposomes, polymeric micelles, and amphiphilic polymers have been constructed with stimuli-responsive functions, including labile crosslinks and core-blockers, in $\mathrm{pH}$, light, or redox environments (5-7). Furthermore, to date, bioinspired mineralized hybrid materials have expanded the development of smart nanocarriers in biotechnology and nanomedicine for advanced biomedical applications $(8,9)$.

Biomineralization is a naturally important biological process by which living organisms develop biominerals [calcium carbonate $\left(\mathrm{CaCO}_{3}\right)$, silica $\left(\mathrm{SiO}_{2}\right)$, calcium phosphate $(\mathrm{CaP})$, etc.] to strengthen their structures, as found in the formation of bone, teeth, shell, and diatoms (10). A distinct property of biominerals, the aqueous solubility of $\mathrm{CaCO}_{3}$ or $\mathrm{CaP}$ minerals largely depends on $\mathrm{pH}$ (11-14) (Figure 1). For instance, the minerals maintain their crystalline structure at physiological $\mathrm{pH}$, whereas they start dissociating into nontoxic ionic species around or below weak acidic $\mathrm{pH}$ levels (11). It is also known that $\mathrm{CaCO}_{3}$ mineral reacts with protons and decomposes in an acid environment, generating carbon dioxide $\left(\mathrm{CO}_{2}\right)$ gas (12). Thus, these unique characteristics of biominerals can offer researchers 


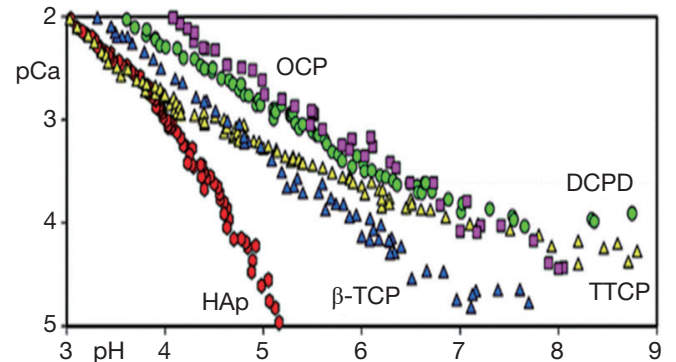

Figure 1 pH-dependent solubility of biominerals. Solubility of calcium phosphate according to changes in $\mathrm{pH}$. Reproduced with permission from (13).

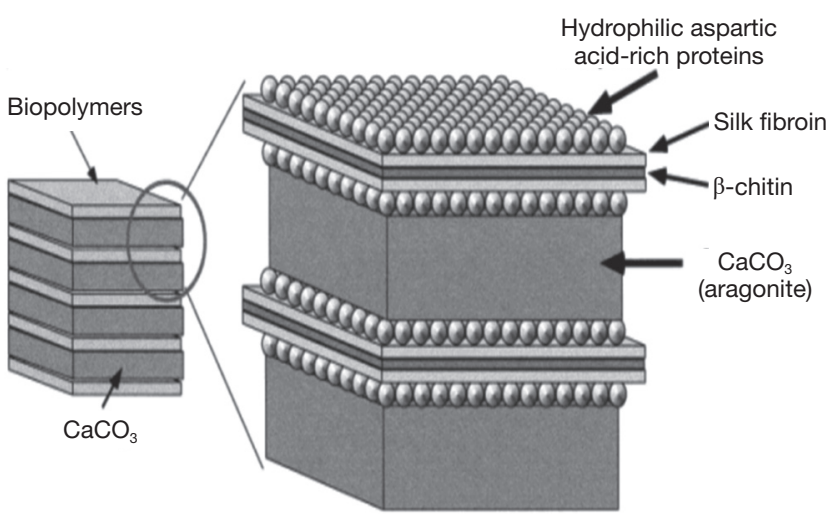

Figure 2 Hybrid structure of natural biominerals. Organicinorganic hybrid structures of the abalone shell. Reproduced with permission from (20).

with interesting and promising strategy for the development of stimuli-responsive hybrid biomaterials. In this article, we address the understanding of biomineral formation and its mechanism in nature. Then, the biomedical applications of biomimetic mineralized hybrid nanocarriers are presented.

\section{Biominerals and mineral characteristics for nanomedicine}

It is known that living organisms produce a wide range of specially designed inorganic-organic hybrid structures through the mineralization process in nature. The biomineralization process is applied for a variety of purposes, such as photonics, mechanical support, and protection of the soft parts of the body (15). The formation process of the bone or shell is vital for building the skeleton of the body, which uses both inorganic $\left(\mathrm{CaCO}_{3}\right.$, and $\left.\mathrm{CaP}\right)$ and organic (proteins, lipids, and carbohydrates) materials
(16-18). $\mathrm{CaCO}_{3}$ and $\mathrm{CaP}$ are used in combination with organic polymers, such as chitin and collagen, to give structural support to bones and shells $(19,20)$. The hard parts of these minerals are living structures that undergo progressive demineralization and remodeling in response to environmental influences and biological environments. A representative example to explain the biomineralization is the structure of the abalone shell. The structures of the inner and outer shells of abalone are formed by $\mathrm{CaCO}_{3}$, proteins, and natural organic materials that exist between the $\mathrm{CaCO}_{3}$ gaps (Figure 2). The organic template consists of chitin layers between the alanine-rich proteins and the silk-like glycine-rich protein, and the outer surface of the template is coated by hydrophilic poly(aspartic acid) macromolecules. Crystallization of $\mathrm{CaCO}_{3}$ mineral is formed by the binding of $\mathrm{CO}_{3}{ }^{2-}$ ions to the surface of the anionic poly(aspartic acid) and subsequent binding of $\mathrm{Ca}^{2+}$ ions. In addition, as another example, natural bone is formed from apatite crystals $(\mathrm{CaP})$ having a specific orientation by biomineralization at the surface of the collagen fibril, which consists of self-assembled collagen triple helices (21).

Recently, $\mathrm{CaP}$ - and $\mathrm{CaCO}_{3}$-mineralized hybrid systems have attracted increasing interest in the field of nanotechnology and biomedical science for the development of novel nanocarriers system because introduction of bioinspired mineralization enables nanocarriers to maintain structural robustness under physiological $\mathrm{pH}(\mathrm{pH}$ 7.4) and selectively dissolve under the acidic $\mathrm{pH}$ of the intracellular endo/lysosome or tumoral region. Therefore, from the knowledge of the natural hybrid structures and biomineral characteristics, we describe a novel concept of mineralized hybrid nanocarriers system for efficient drug delivery to and imaging of the targeted disease in next each section.

\section{Mineralized liposomal nanocarrier systems}

As a pioneering work, a biomimetic mineralization process for hybrid nanosized liposomes covered with $\mathrm{CaP}$ layers was firstly reported by Schmidt et al. (22,23). 2-dioleoyl-snglycero-3-phosphate (DOPA)-based liposomes were used as a template for $\mathrm{CaP}$ mineral deposition. $\mathrm{CaP}$ mineralization on the surface of the liposomes was initiated by electrostatic localization of calcium ions at anionic phosphate moieties of liposomal surfaces, and the subsequent addition of phosphoric acid induced the formation of the $\mathrm{CaP}$ mineral layer. As a result, liposomal nanoparticles uniformly coated with an outer layer of $\mathrm{CaP}$ were formed, and the thickness of the $\mathrm{CaP}$ mineral layer gradually increased with increasing 

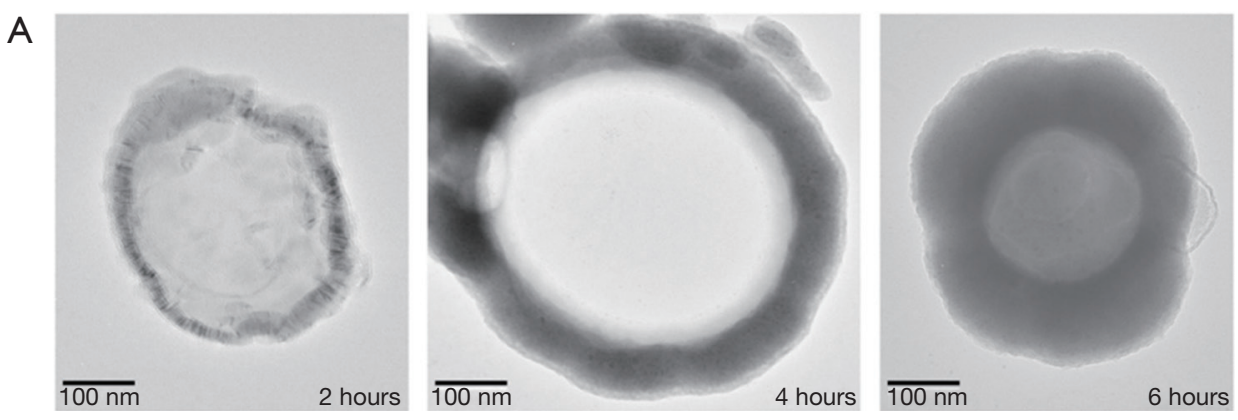

B

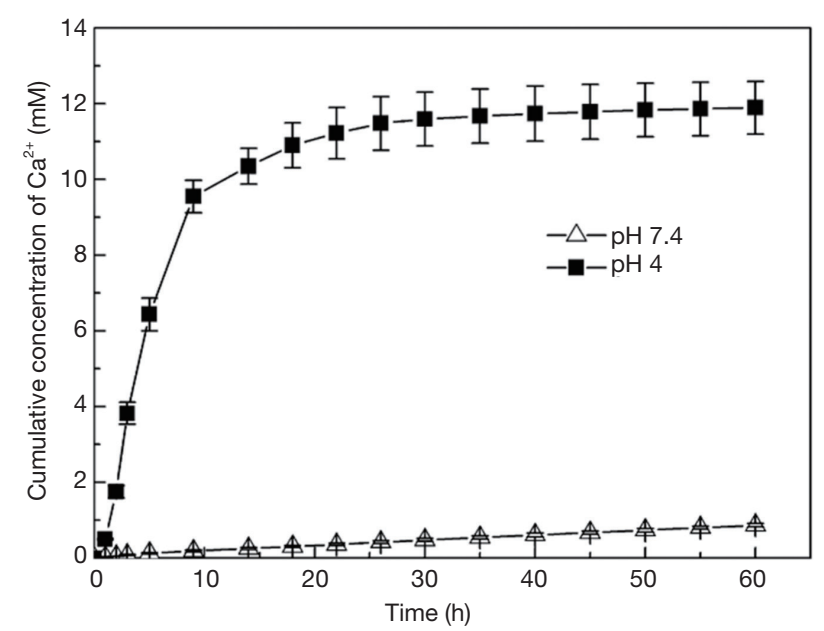

Figure 3 HA mineralized liposome. (A) TEM images of HA layer thickness from HACL after different reaction times; (B) calcium ion dissolution from HACL in PBS (pH 7.4) and acetic buffer solution ( $\mathrm{pH} 4.0)$. Reproduced with permission from (24).

time of the $\mathrm{CaP}$ mineralization process.

In addition, $\mathrm{Xu}$ et al. reported the kinetics of $\mathrm{pH}-$ controlled drug release from hydroxyapatite (HA) $\left[\mathrm{Ca}_{10}\left(\mathrm{PO}_{4}\right)_{6}(\mathrm{OH})_{2}\right]$-mineralized liposome (HACL) (24) (Figure 3). Although these authors used indomethacin (IMC) as a model drug for this mineralized liposomal delivery system, this work is a valuable guide for the development of diverse $\mathrm{pH}$-responsive mineralized nanocarriers for therapy and imaging of cancers. The IMC-loaded liposomes were formed by 1,2-dimyristoyl-sn-glycero-3-phosphate (DMPA) and 1,2-dimyristoyl-sn-glycero-3-phosphocholine (DMPC), and $\mathrm{CaCl}_{2}$ and $\mathrm{KH}_{2} \mathrm{PO}_{4}$ were induced for the HA mineralization layer. After mineralization, the resulting particles showed that the thickness of the inorganic mineral layer was dependent on the reaction time. The particle size increased from 163 to $585 \mathrm{~nm}$, and the zeta potential was changed from -38 to $-4 \mathrm{mV}$ after HA mineralization. For the result of the IMC drug release behavior of the liposome, the nonmineralized liposome demonstrated fast drug release $(70 \%)$ within 5 h. In contrast, the mineralized liposome showed sustained drug release of over $20 \mathrm{~h}$. Because the dissolution of the inorganic HA minerals was also accelerated under acidic $\mathrm{pH}$ conditions, a faster drug release rate for HACL was observed at $\mathrm{pH} 4.0$ than at $\mathrm{pH}$ 7.4. These results indicated that the mineralized layer of the liposome controlled the kinetics of drug release by adjusting the $\mathrm{pH}$ levels.

\section{Mineralized polymer nanocarriers for drug delivery}

In recent years, functional polymeric micelles assembled by amphiphilic block copolymers have led to the fabrication of smart nanomaterials that can enhance the delivery efficacy of therapeutic drugs $(25,26)$. In particular, polymeric micelles have diverse advantages for cancer treatments owing to their ability to efficiently escape from rapid renal clearance and nonspecific uptake by the reticuloendothelial system (RES). These unique properties enable the passive targeting and enhanced permeability and retention (EPR) 
A
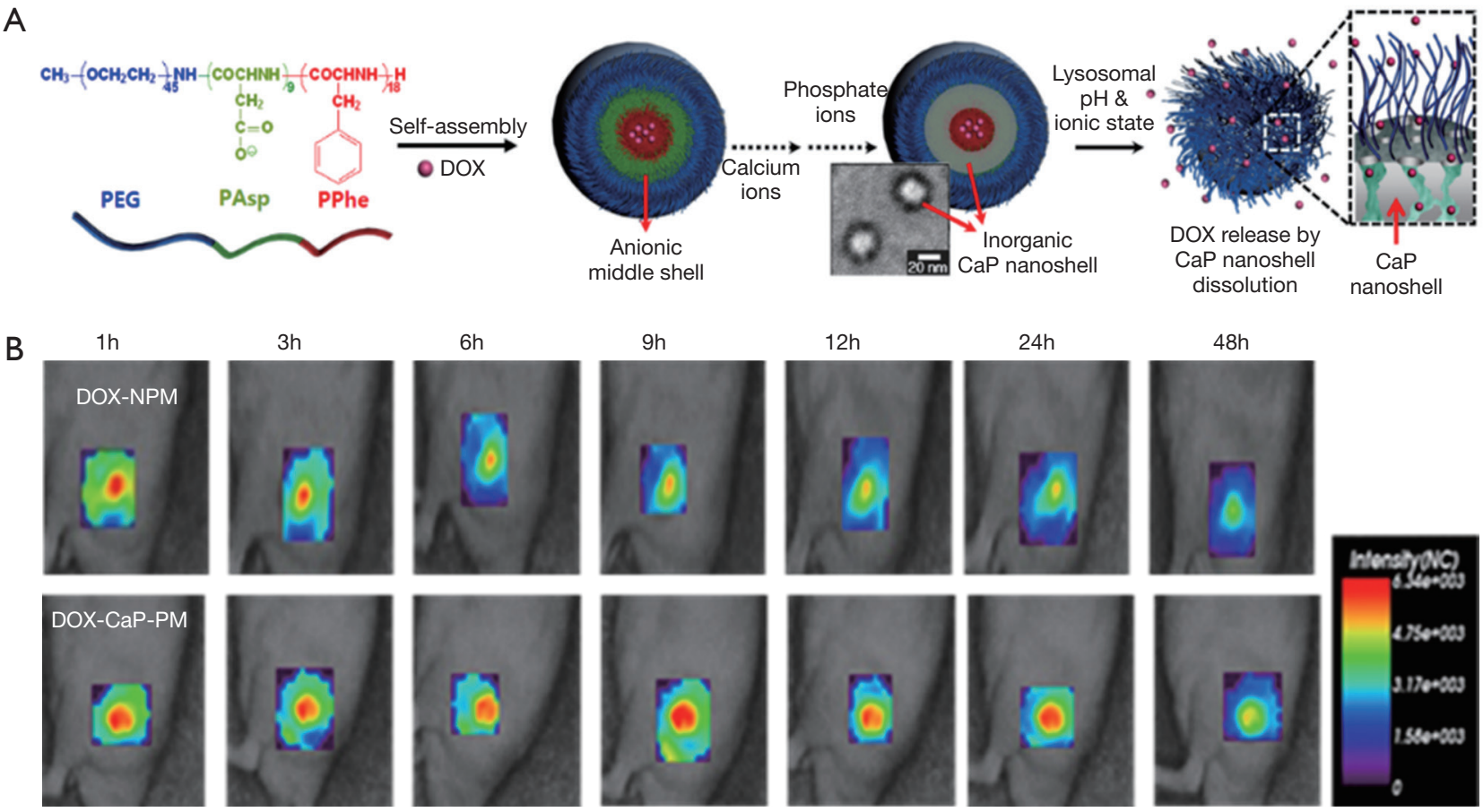

C

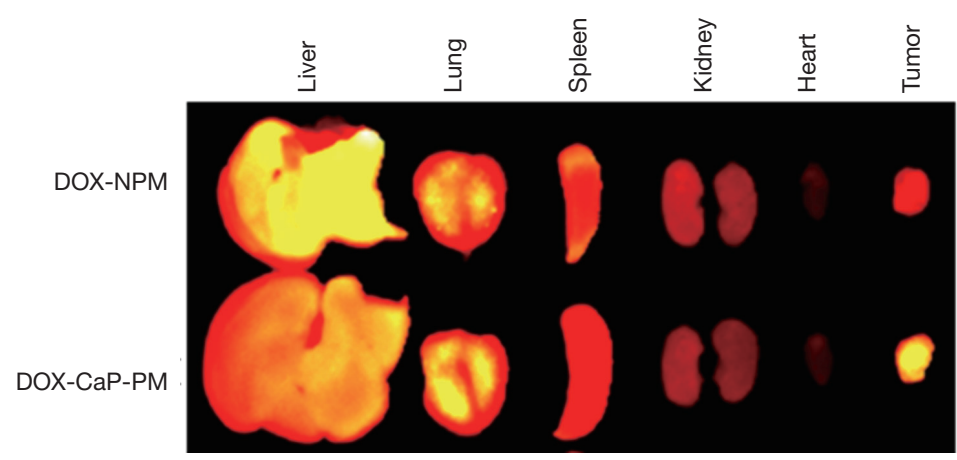

Figure 4 Mineralized self-assembled polymeric nanocarriers for cancer therapy. (A) Illustration of spatial mineralization of drug-loaded polymeric micelles and drug release facilitated under specific intracellular conditions; (B) in vivo NIRF images of tumors from MDAMB-231 tumor-bearing mice after intravenous injection of Cy5.5-DOX-NPM and Cy5.5-DOX-CaP-PM; (C) ex vivo images of normal organs and tumors after 3 days postinjection of DOX-NPM and DOX-CaP-PM. Reproduced with permission from $(28,29)$.

effect for effective tumor treatments (27). However, most polymeric micelles suffer from low structural stability in the bloodstream (28). In addition, drug release is induced upon intravenous administration, resulting in drug leakage at unwanted sites. By increasing the stability of micelles and minimizing the loss of therapeutic drugs at unwanted sites, Lee et al. demonstrated that spatially selective mineralization of polymeric micelles produced a highly biocompatible and robust hybrid structure that can controllably release anticancer drugs or therapeutic agents $(28,29)$ (Figure 4). In this work, to prepare polymeric micelles as a nanotemplate for the mineralization process, the triblock copolymer of poly(ethylene glycol)-b-poly(Laspartic acid)-b-poly(L-phenylalanine) (PEG-b-PAsp-bPPhe) was utilized (29). Poly(amino acid)s and PEG were selected as polymer components owing to their low toxicity and biocompatibility (28). CaP mineral deposition was processed by selective electrostatic localization of calcium ions at the anionic shell domain of Asp moieties. The subsequent addition of $\mathrm{Na}_{2} \mathrm{HPO}_{4}$ as a phosphate anion source initiated the formation of double ionic layers on the surface on the PAsp middle shells, thereby increasing the 


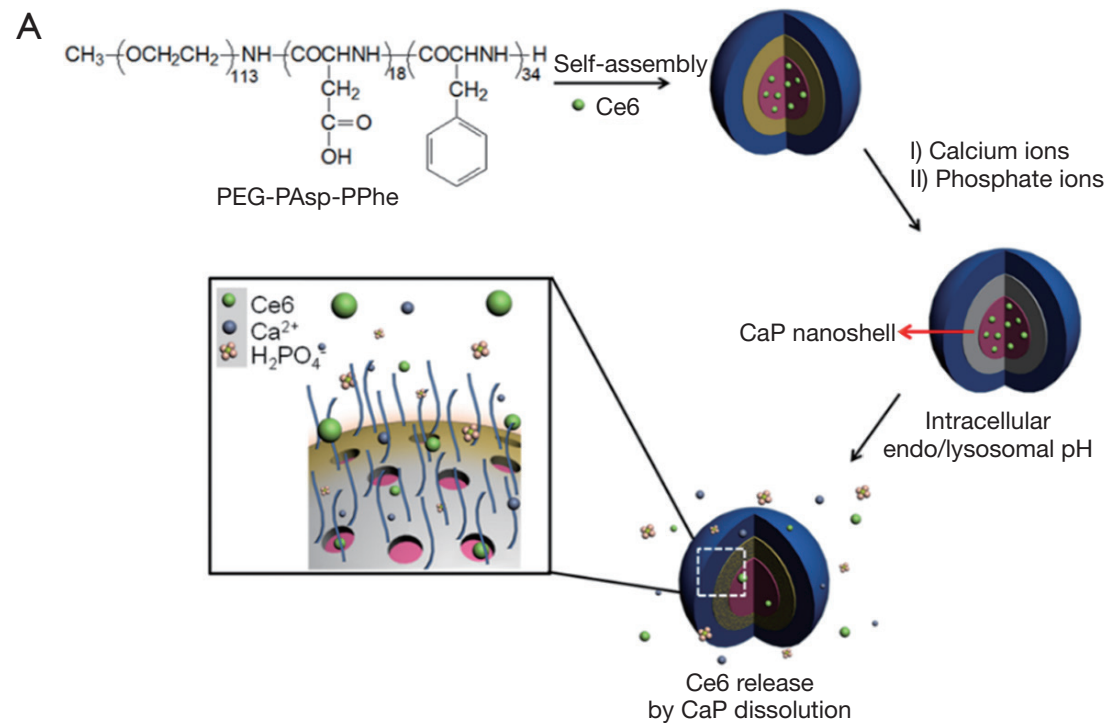

B

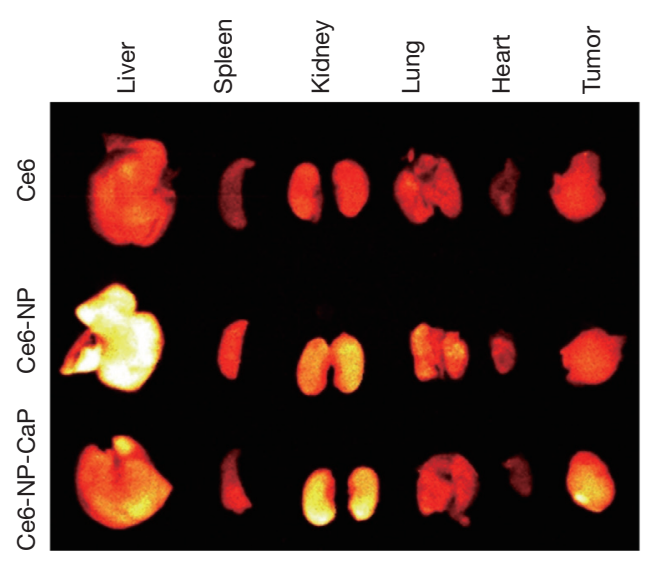

Figure 5 CaP-mineralized polymeric nanocarriers for photodynamic therapy. (A) Fabrication of CaP-Ce6-loaded polymeric micelles; (B) ex vivo images of organs and tumor tissues at 1 day postinjection of Ce6, Ce6-NP, and Ce6-NP-CaP. Reproduced with permission from (30).

ionic concentration above the critical saturation point for $\mathrm{CaP}$ mineral growth. Doxorubicin (DOX), an anticancer drug, was simply loaded into the hydrophobic PPhe domain of polymeric micelles using the dialysis method before $\mathrm{CaP}$ mineralization. The mean hydrodynamic diameter was $31.2 \mathrm{~nm}$, and X-ray spectroscopy (EDS) indicated that the mineralized micelles contained calcium and phosphate elements, which belong to $\mathrm{CaP}$ minerals. The DOX release rate from nonmineralized polymeric micelles (DOX-NPM) did not notably exhibit differences in release patterns between extracellular ( $\mathrm{pH}$ 7.4) and lysosomal environments $(\mathrm{pH} 4.5)$. On the other hand, mineralized polymeric micelles (DOX-CaP-PM) effectively inhibited drug release in the extracellular environment at $12 \mathrm{~h}$ by $70 \%$.

The in vivo tumor accumulation of the DOX-CaP-PM labeled with a near-infrared fluorescent (NIRF) moiety, Cy5.5, was observed in MDA-MB231 tumor-bearing mice. The result of optical imaging indicated that the DOXCaP-PM showed enhanced tumor accumulation owing to prolonged systemic circulation in the bloodstream and an enhanced permeation and retention (EPR) effect compared with the DOX-NPM (29). Moreover, the DOX-CaP-PM exhibited an enhanced therapeutic effect in tumor-bearing mice compared with both free DOX and DOX-NPM.

For efficient photodynamic therapy (PDT), a similar mineralization approach was applied to the photosensitizer (PS)-loaded polymeric micelles (Figure 5) (30). Chlorin e6 (Ce6) was loaded into the polymeric micelles of PEG-PAsp-
PPhe, and then, $\mathrm{CaP}$ minerals were deposited on the middle shell of the polymeric micelles. The Ce6-loaded CaPmineralized micelles (Ce6-NP-CaP) displayed an enhanced stability of their structure and $\mathrm{pH}$-dependent release patterns of Ce6. The MCF-7 cells treated with Ce6-NP-CaP with near-infrared (NIR) laser irradiation exhibited a dramatic decrease in cell viability. Moreover, after the Ce6-NP$\mathrm{CaP}$ administered to the MCF-7 tumor-bearing mice by intravenous injection, in vivo biodistribution was monitored. NIRF images indicated that the Ce6-NP-CaP showed tumor-targeting ability compared to both free Ce6 and nonmineralized Ce6-loaded polymeric micelles (Ce6-NP).

More recently, Nam et al. developed a novel polymer nanotemplate for $\mathrm{CaP}$-mineralized nanocarriers composed of a poly(3,4-dihydroxy-1-phenylalanine) (PDOPA) core and a poly(ethylene glycol) (PEG) shell (Figure 6) (31). The catecholic amino acid DOPA originates from the adhesive foot protein (Mefp-5, Mytilus edulis foot protein-5) of marine mussels (32). It has been reported that the catecholic $\mathrm{OH}$ of DOPA can bind to various metal ions $(\mathrm{Ca}, \mathrm{Mn}$, $\mathrm{Fe}, \mathrm{Zn}$, and $\mathrm{Ti}$ ) to form a strong coordinate complexation $(33,34)$. The strategy for successful $\mathrm{CaP}$ mineralization onto PEG-PDOPA polymer nanocarriers was based on the strong binding of $\mathrm{Ca}^{2+}$ ions with $\mathrm{OH}$ of DOPA, which serves as a stable mineralization site of nucleation and growth for the CaP mineral core. DOX was loaded into the core of polymer nanocarriers (NPs) during self-assembly of PEGPDOPA. In addition, $\mathrm{CaP}$ minerals were effectively induced 

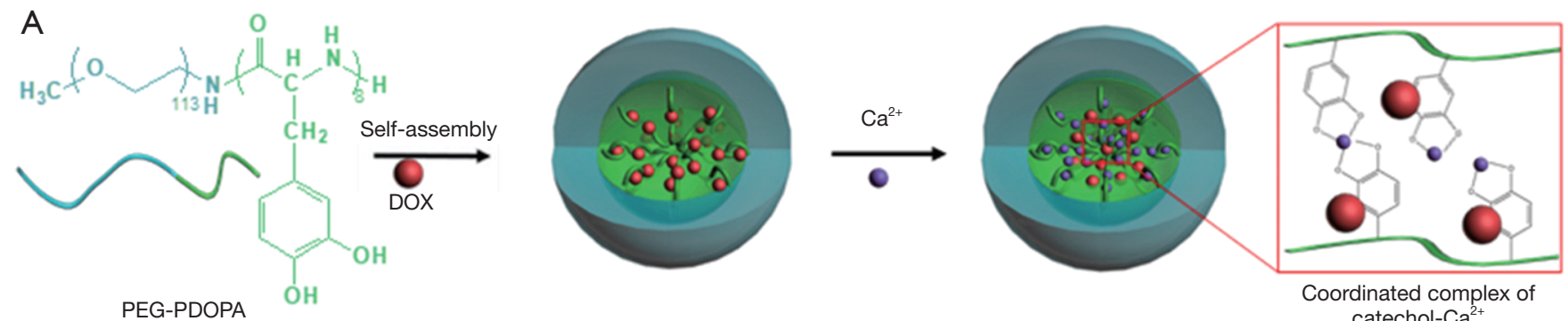

$\mathrm{PO}_{4}^{3-} \mid \mathrm{g}$

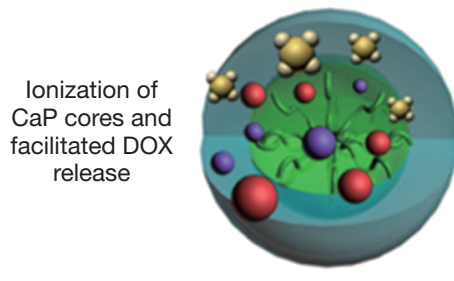

Endosomal $\mathrm{pH}$

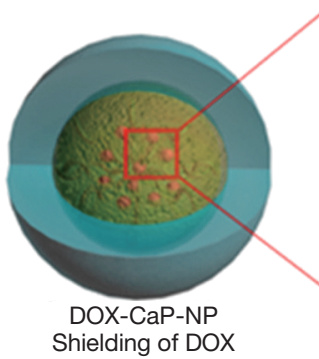

by $\mathrm{CaP}$ cores

B
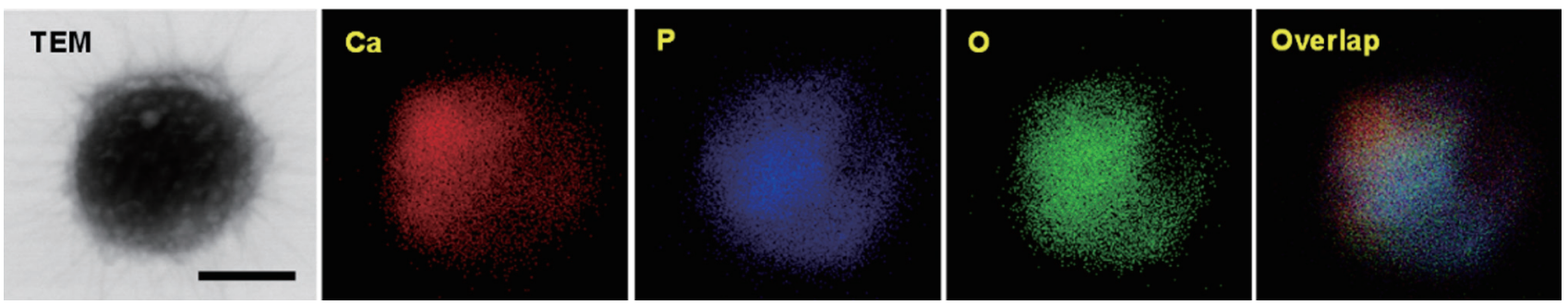

Figure 6 CaP-mineralized mussel-inspired poly(L-DOPA)-PEG polymer nanocarriers for intracellular delivery of DOX. (A) Illustration of the fabrication of $\mathrm{CaP}$-mineralized DOX-loaded polymer nanocarriers and facilitated drug release under specific intracellular conditions; (B) energy-dispersive X-ray photoelectron spectroscopy (EDX) mapping images from DOX-CaP-NPs indicate the presence of CaP elements (scale bar: $50 \mathrm{~nm}$ ). Reproduced with permission from (31).

on the PDOPA core of the PEG-PDOPA nanocarriers. The release of DOX from DOX-loaded CaP-mineralized nanocarriers (DOX-CaP-NPs) was triggered at endosomal $\mathrm{pH}$ (5.0), whereas the $\mathrm{CaP}$ mineral core stably maintained the structure of DOX-CaP-NPs, which resulted in the inhibition of drug leakage at extracellular $\mathrm{pH}$. These DOX$\mathrm{CaP}-\mathrm{NPs}$ enhanced cellular uptake and cell cytotoxicity in SCC-7 head and neck cancer cells.

\section{Mineralized hybrid nanocarriers for protein delivery}

Despite their excellent therapeutic effect, target specificity, and biosafety, protein drugs have limitations in clinical applications because they are degraded by proteolytic enzymes and have difficulty in permeating into targeted cells. To overcome these limitations of protein drugs, Koo et al. introduced cytochrome c-loaded $\mathrm{CaCO}_{3}$ mineralized nanocarriers (Cyt c MNPs) for effective intracellular protein drug delivery (35). They synthesized a block copolymer PEG-PAsp for a nanotemplate $\mathrm{CaCO}_{3}$ mineralization approach. Cytochrome c (Cyt c), an apoptosis-inducing protein (36), was loaded in situ into the $\mathrm{CaCO}_{3}$ mineral core during the nucleation and growth of $\mathrm{CaCO}_{3}$ minerals via PEG-PAsp-template mineralization in the presence of $\mathrm{Ca}^{2+}$ and $\mathrm{CO}_{3}{ }^{2-}$. The resulting mineralized nanoparticles had a spherical shape with a size of approximately $277.1 \mathrm{~nm}$. The mineral core of the Cyt c MNPs sufficiently inhibited the release of Cyt c at physiological $\mathrm{pH}$ (7.4), but the dissolution of $\mathrm{CaCO}_{3}$ 

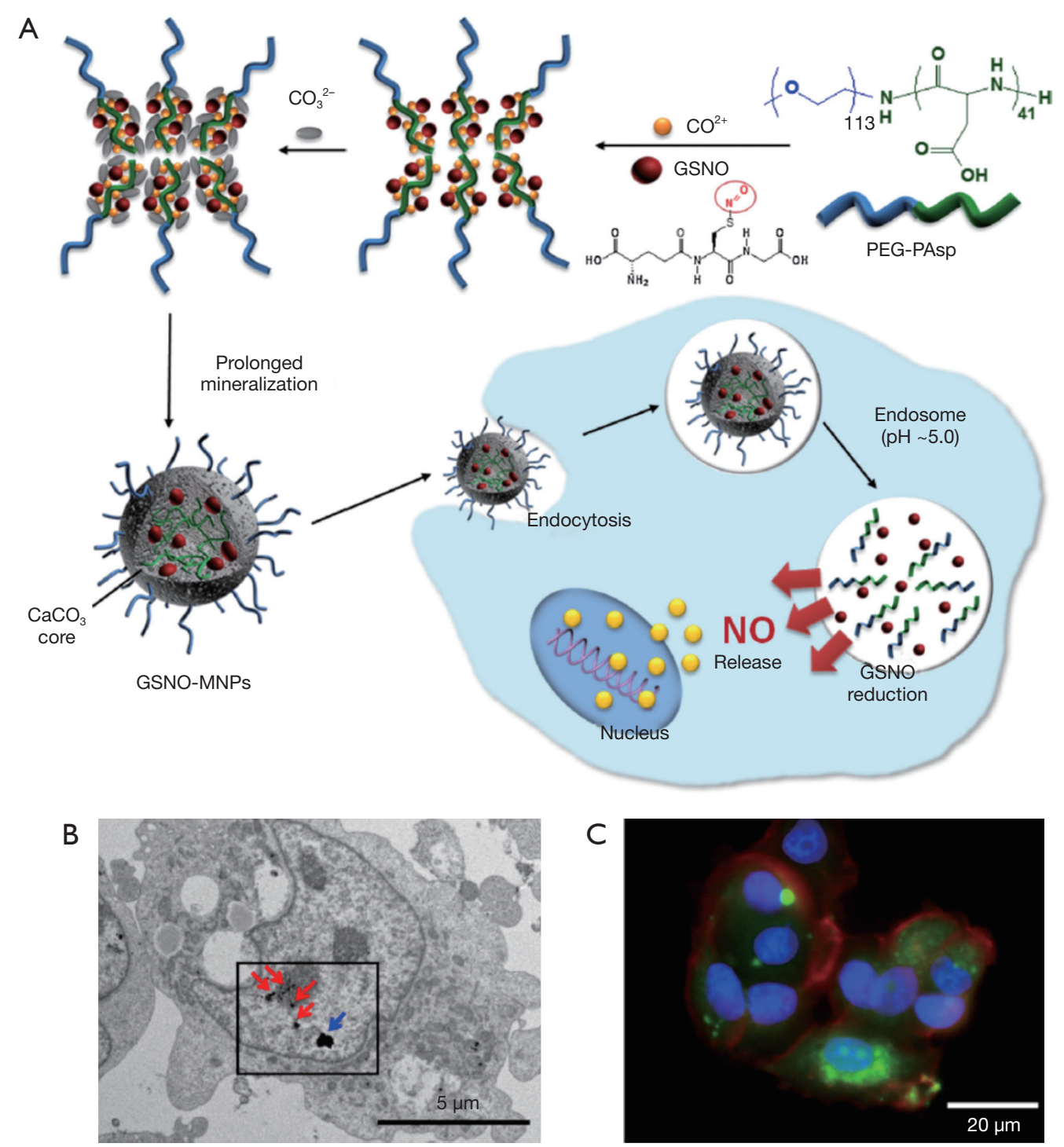

Figure 7 Mineralized nanoparticles for intracellular nitric oxide delivery. (A) Illustration of the fabrication process for GSNO-loaded $\mathrm{CaCO}_{3}$-mineralized nanoparticles (GSNO-MNPs) and intracellular NO release; (B) TEM images of MCF-7 cells treated with the GSNOMNPs for $30 \mathrm{~min}$ (red arrows: individual GSNO-MNP, blue arrow: aggregates of GSNO-MNPs); (C) CLSM image of MCF-7 cells treated with GSNO-MNPs and DAF-FM DA. Reproduced with permission from (37).

triggered drug release at endosomal $\mathrm{pH}$ (5.0). With the capability of efficient cellular uptake and endosomal escape, this system successfully induced apoptosis and killed the MCF-7 cells.

\section{Mineralized hybrid nanocarriers for nitric oxide delivery}

Very recently, nitric oxide (NO)-generating $\mathrm{CaCO}_{3}$ mineralized nanocarriers were developed to treat targeted cancer cells (Figure 7) (37). It has been known that NO is an endogenously produced free radical that plays multiple roles, such as neurotransmission, vasodilation, and regulation of proliferation and apoptosis of cells $(38,39)$. In addition, NO has been reported to have an inhibitory effect on tumor growth by inducing apoptosis $(40,41)$. However, despite the therapeutic potential of $\mathrm{NO}$, the clinical applications of $\mathrm{NO}$ are limited by its instability and short 
half-life in the body (42). In this work, S-nitrosoglutathione (GSNO), one of the NO donors, was utilized due to its endogenous nontoxicity $(43,44)$. Moreover, to improve its stability in aqueous solution and specificity for target cancer cells, a mineralization approach was applied for generation of NO delivery nanocarriers (37). GSNOloaded $\mathrm{CaCO}_{3}$-mineralized nanoparticles (GSNO-MNPs) were successfully prepared using the PEG-PAsp-template in situ mineralization process by the addition of calcium cations, carbonate anions, and GSNO. The GSNOMNPs had a hydrodynamic size of approximately $248.8 \mathrm{~nm}$ and spherical morphology confirmed by dynamic light scattering and TEM. Moreover, TEM-associated energydispersive $\mathrm{X}$-ray spectroscopy (EDX) analysis confirmed the elemental signals $(\mathrm{Ca}, \mathrm{C}$, and $\mathrm{O})$ of $\mathrm{CaCO}_{3}$ minerals and the $\mathrm{S}$ signal from GSNO. A stability test of GSNOMNPs showed that GSNO loaded within the mineral core had improved stability compared with that of free GSNO. The release of NO from GSNO-MNPs was evaluated at endosomal $\mathrm{pH}$ and in the reducing environment of the cytosol ( $\mathrm{pH}$ of 5.0 and ascorbic acid of $5 \mathrm{mM}$ ). The GSNOMNPs exhibited rapid NO release of up to $85.3 \%$ for $24 \mathrm{~h}$ under intracellular conditions. The result indicated that at endosomal $\mathrm{pH}$, the $\mathrm{CaCO}_{3}$ mineral core of MNPs was dissolved, and the release of GSNO was reduced by ascorbic acid (37). The TEM image showed that the GSNO-MNPs were efficiently internalized into MCF-7 cells by the endocytosis process. Moreover, after cellular uptake of GSNO-MNPs, $\mathrm{NO}$ was generated by a reduction of GSNO in GSNO-MNP-treated MCF-7 cells and was monitored by the reaction product between $\mathrm{NO}$ and 4-amino-5-methylamino-2',7'-difluorofluorescein diacetate (DAF-FM DA). Next, to verify the sensitizing effect of NO and to confirm the improved cell cytotoxicity of DOX in MCF-7 cells, the MCF-7 cells were treated with GSNOMNPs for $12 \mathrm{~h}$ before DOX treatment. The GSNO-MNPs enhanced the cell cytotoxicity of DOX throughout a range of DOX concentrations compared to control groups (treated with DOX only or with GSNO-free MNPs + DOX-treated MCF-7 cells).

\section{Mineralized hybrid nanoparticles for magnetic resonance imaging}

To increase the sensitivity and specificity of magnetic resonance imaging (MRI) probes for tumor imaging, $\mathrm{Mi}$ et al. designed $\mathrm{CaP}$-mineralized nanoparticles into which diethylenetriaminepentaacetic acid gadolinium (III) (Gd-DTPA) was incorporated (Figure 8) (45). GdDTPA-incorporated CaP nanoparticles (Gd-DTPA/ $\mathrm{CaP}$ ) were fabricated via a simple two-step method, which combined the PEG-PAsp block copolymertemplated $\mathrm{CaP}$ mineralization step with Gd-DTPA, followed by a hydrothermal process. In particular, the hydrothermal treatment endowed Gd-DTPA/CaP with enhanced structural stability in aqueous environments. In a molecular relaxivity $\left(\mathrm{r}_{1}\right)$ study, the $\mathrm{r}_{1}$ value of $\mathrm{Gd}$ DTPA from Gd-DTPA/CaP was 6 times higher than that of free Gd-DTPA. $T_{1}$-weighted MR images indicated that at the same concentration, Gd-DTPA/CaP showed much higher contrast enhancement than free Gd-DTPA. Furthermore, Gd-DTPA/CaP gradually increased the MR contrast of the tumor position after intravenous injection of Gd-DTPA/CaP to C-26 tumor xenograft mice, while the MR image of the tumor position from the free GdDTPA-treated group with 4 times higher dose than that of Gd-DTPA/CaP showed no signal enhancement. At $4 \mathrm{~h}$ postinjection, the tumor-to-muscle signal ratio of $\mathrm{Gd}$ DTPA/CaP increased more than $40 \%$.

Based on the results of these mineralized nanoparticles, the same group developed an improved mineralized hybrid MRI agent system. $\mathrm{Mn}^{2+}$-doped $\mathrm{CaP}$-mineralized nanoparticles (PEGMnCaP) were developed using poly(ethylene glycol)-b-poly(glutamic acid) copolymers [PEG-b-P(Glu)] with mineralization of $\mathrm{Mn}^{2+}, \mathrm{Ca}^{2+}$ and $\mathrm{HPO}_{4}{ }^{2-}$ and subsequent hydrothermal treatment (Figure 9) (46). The resulting particles showed that the release of $\mathrm{Mn}^{2+}$ was $\mathrm{pH}$ dependent and accelerated in an acidic environment, resulting from the dissolution of the CaP mineral core. In $T_{1}$-weighted MRI, higher contrast enhancement of tumor regions was obtained for the PEGMnCaP-treated group compared with groups treated with both Gd-DTPA and PEGylated $\mathrm{Mn}_{2} \mathrm{O}_{3}$ nanoparticles $\left(\mathrm{PEGMn} \mathrm{O}_{3}\right)$. The partially higher MR contrast regions than other regions in the tumors were correlated with both the hypoxic area and the high lactate level in tumor tissues. This is because the production of lactate and deficiency in environmental oxygen in the tumor tissue induced partial hypoxia, which resulted in an acidic microenvironment in tumors (47). Furthermore, $\mathrm{PEGMn} \mathrm{O}_{3}$ detected metastatic tumors in the liver induced by spreading C26 colon cancer cells compared to gadolinium ethoxybenzyl dimeglumine (Gd-EOB-DTPA), used for clinical hepatobiliary magnetic resonance probes. 
A

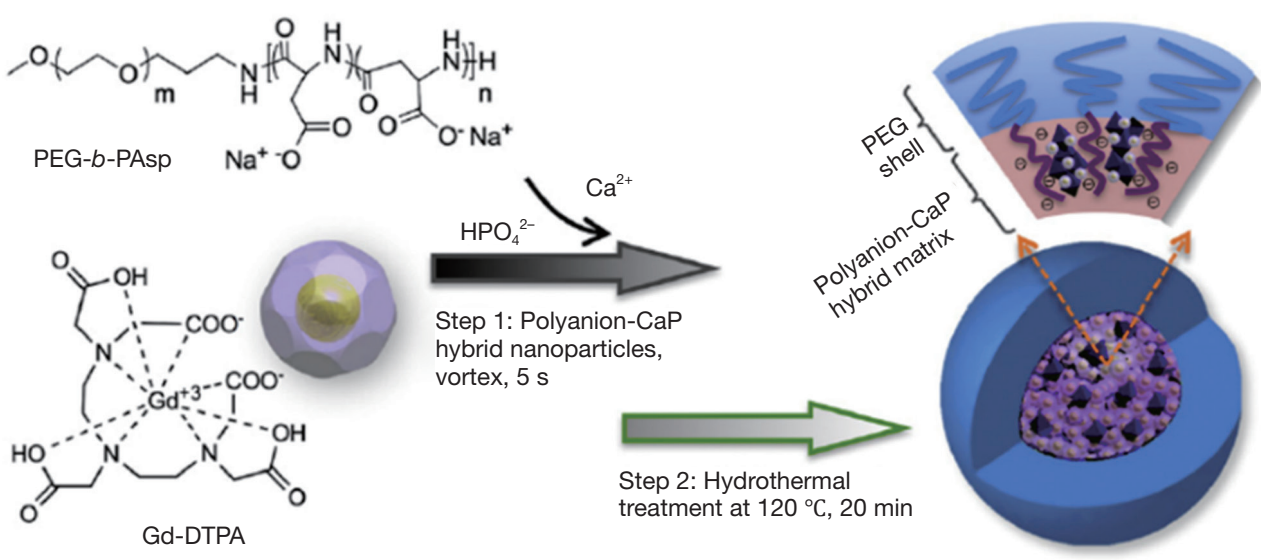

B

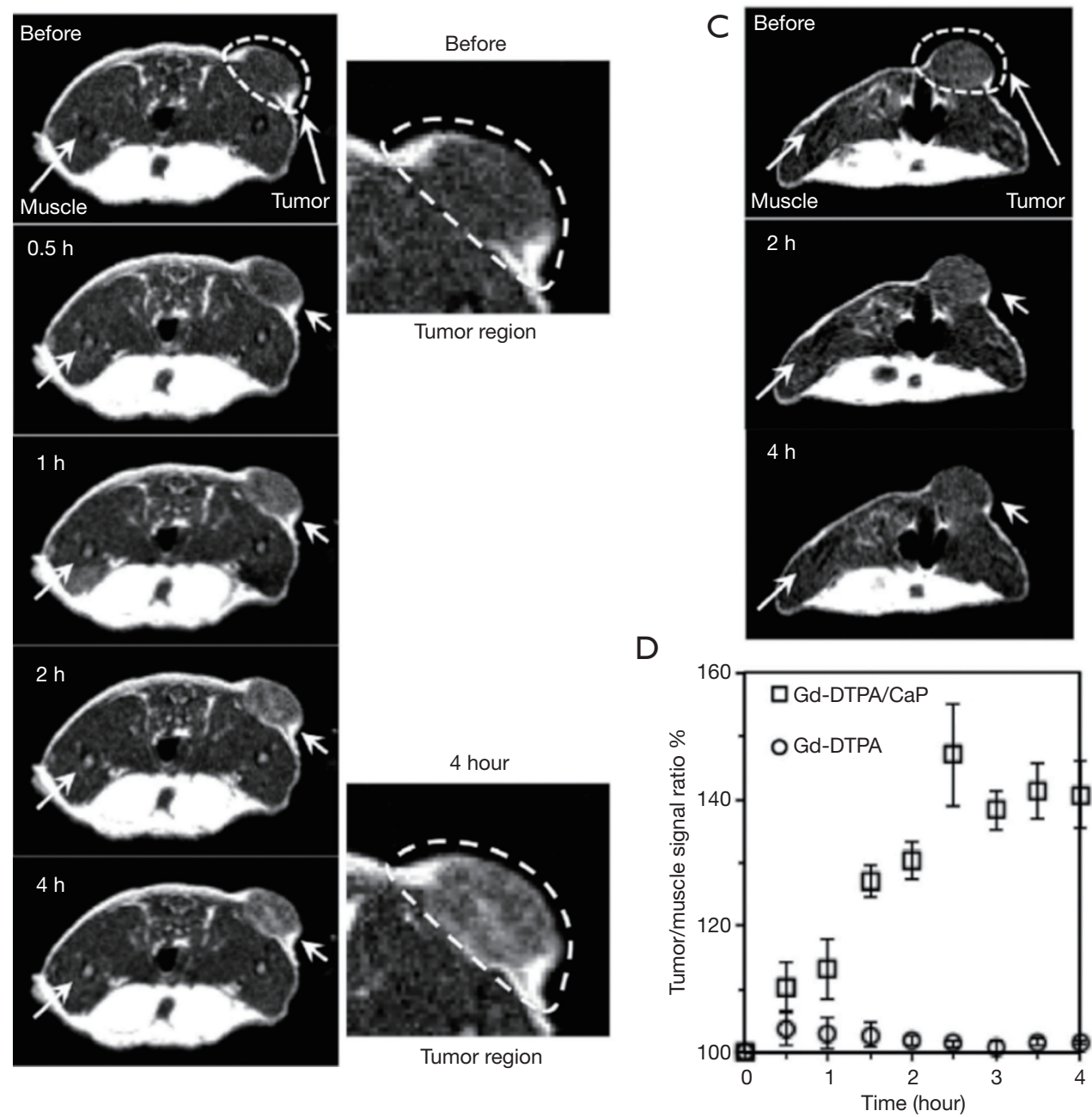

Figure 8 Mineralized hybrid nanoparticles for enhanced MR imaging. (A) Preparation of Gd-DTPA/CaP; (B) in vivo MR images of C-26 xenograft tumor-bearing nude mice after intravenous injection of Gd-DTPA/CaP; (C) in vivo MR images of C-26 xenograft tumor-bearing nude mice after intravenous injection of free Gd-DTPA; (D) tumor-to-muscle signal ratio from MR images. Reproduced with permission from (45). 
A

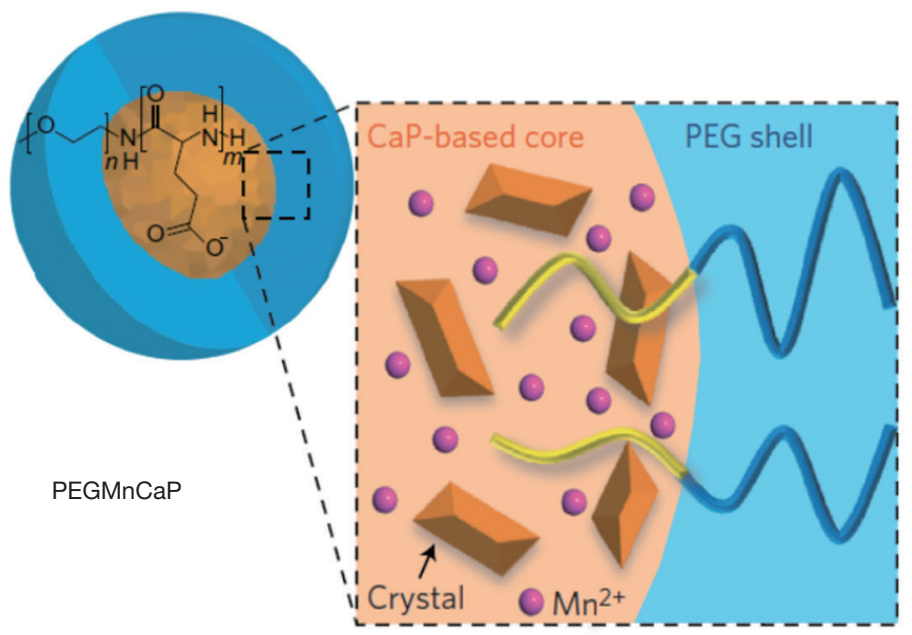

B

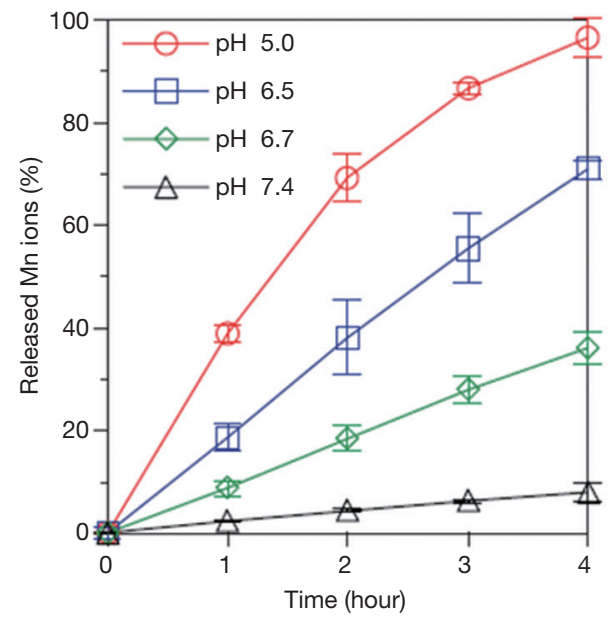

C Pre

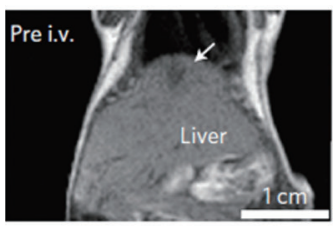

$\mathrm{D}$

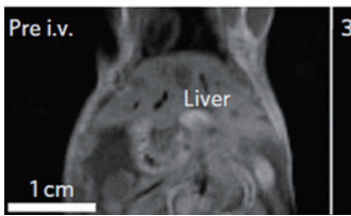

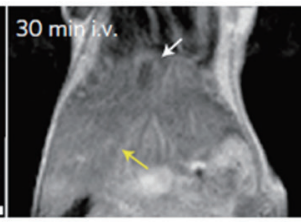

30 min i.v.

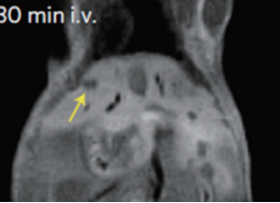

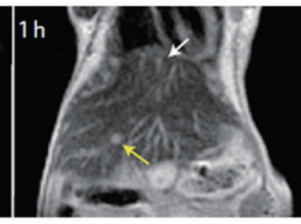
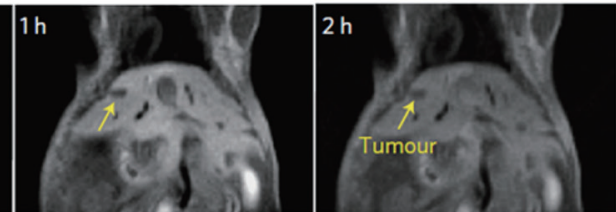

E

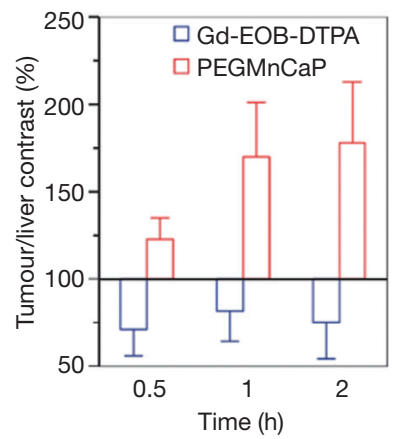

Figure 9 CaP-mineralized hybrid MRI agent. (A) The hybrid structure of PEGMnCaP; (B) release profiles of $\mathrm{Mn}^{2+}$ from PEGMnCaP at various $\mathrm{pH}$ levels; (C) MR images of liver metastasis measured by 1 T MRI; (D) MR images of liver metastasis with the Gd-EOB-DTPA; (E) the tumor-to-liver contrast intensity after the intravenous injection of PEGMnCaP and Gd-EOB-DTPA. Reproduced with permission from (46).

\section{Mineralized nanoparticles for ultrasound imaging (US) and US imaging-guided therapy of cancers}

Theranostics that integrate imaging and therapeutic functions in one system have emerged in the field of nanomedicine for developing novel nanoparticles $(48,49)$. In recent years, $\mathrm{CaCO}_{3}$-mineralized theranostics nanoparticles with spherical shape and sizes of approximately $240 \mathrm{~nm}$ have been developed for ultrasound (US) imaging and cancer therapy (Figure 10) (50). The block copolymer PEGPAsp was applied as a $\mathrm{CaCO}_{3}$ mineralization template. In this study, at physiological $\mathrm{pH}(\mathrm{pH}$ 7.4), the DOXloaded $\mathrm{CaCO}_{3}$-mineralized nanoparticles (DOX-CaCO${ }_{3}-$ $\mathrm{MNPs}$ ) maintained their robust mineral structures, which inhibited the release of DOX owing to the solubility of $\mathrm{CaCO}_{3}$ mineral. However, at tumoral acidic $\mathrm{pH}(\mathrm{pH} 6.8)$, the DOX-CaCO$-M N P$ showed rapid DOX release patterns, which well correlated with the dissolution of $\mathrm{Ca}^{2+}$ ions from the DOX- $\mathrm{CaCO}_{3}$-MNPs. Moreover, US images from the DOX-CaCO$-\mathrm{MNPs}$ were significantly enhanced at tumoral acidic $\mathrm{pH}(\mathrm{pH} 6.8,7.0$, and 7.2) because of sufficient $\mathrm{CO}_{2}$ bubble generation from the DOX-CaCO${ }_{3}$ MNPs (50). In contrast, the DOX-CaCO $3-\mathrm{MNPs}$ did not produce sufficient $\mathrm{CO}_{2}$ gas bubbles, which resulted in no significant contrast in US signals at $\mathrm{pH}$ 7.4. For the in vivo US imaging experiment, after the intratumoral injection of DOX-CaCO$-\mathrm{CHN}_{3}-\mathrm{MN}$ to the tumor tissue of SCC-7 tumor-bearing nude mice, the US contrast enhancement of the tumor site was detected up to $120 \mathrm{~min}$. To confirm the in vivo antitumor effect of the $\mathrm{DOX}-\mathrm{CaCO}_{3}-\mathrm{MNPs}$, DOX-CaCO $3-M N P s$ were injected intratumorally. The 
A
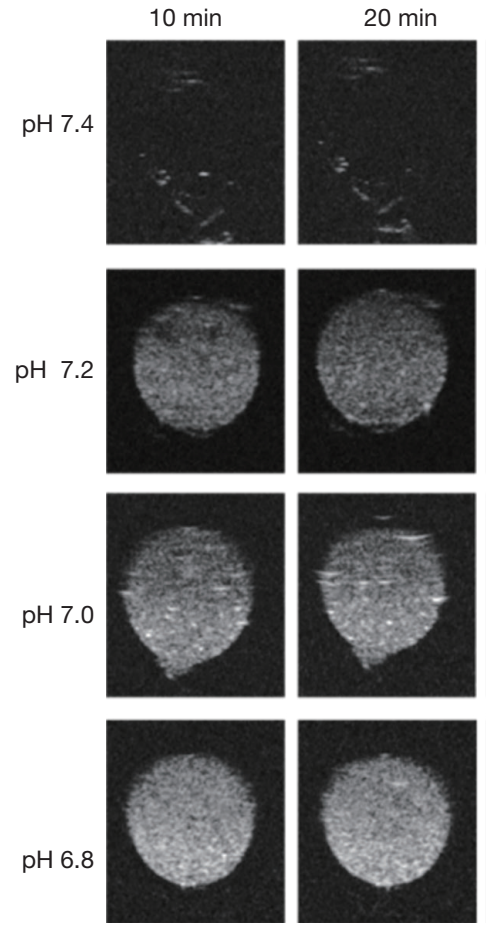

$30 \mathrm{~min}$
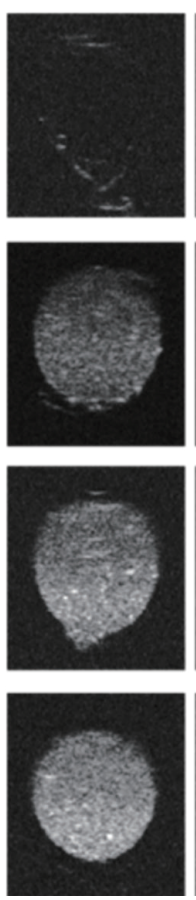

$60 \mathrm{~min}$
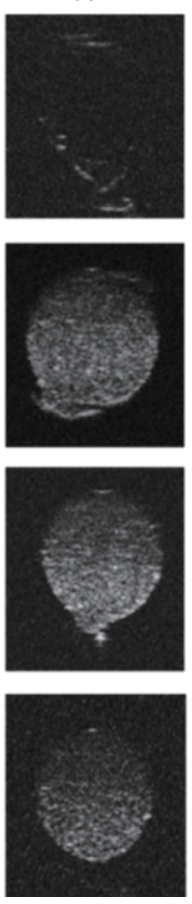

$90 \min$
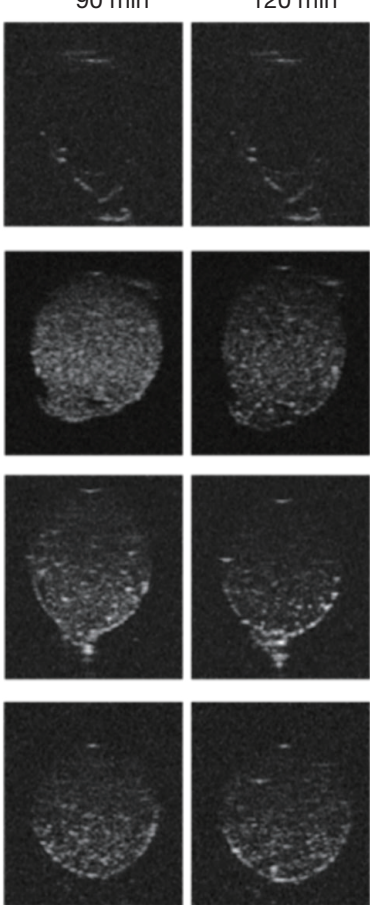

$0 \mathrm{~min}$

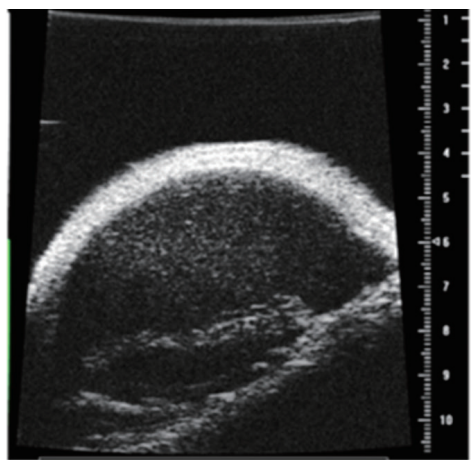

$60 \mathrm{~min}$
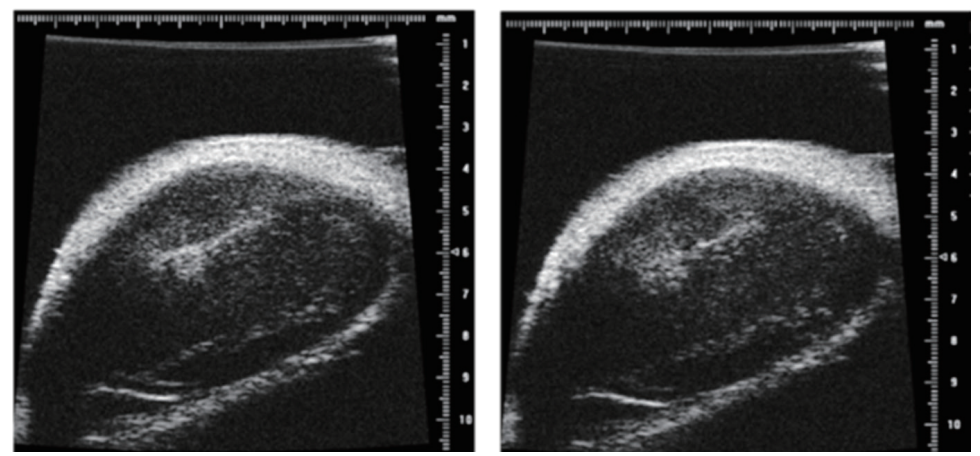

Figure 10 Mineralized theranostic nanoparticles for ultrasound imaging and cancer therapy. (A) In vitro US images from DOX-CaCO $3^{-}$ MNPs at various $\mathrm{pH}$; (B) in vivo US images of the SCC-7 tumor via intratumoral injection of DOX-CaCO $3-\mathrm{MNPs}_{3}$. Reproduced with permission from (50). 
A
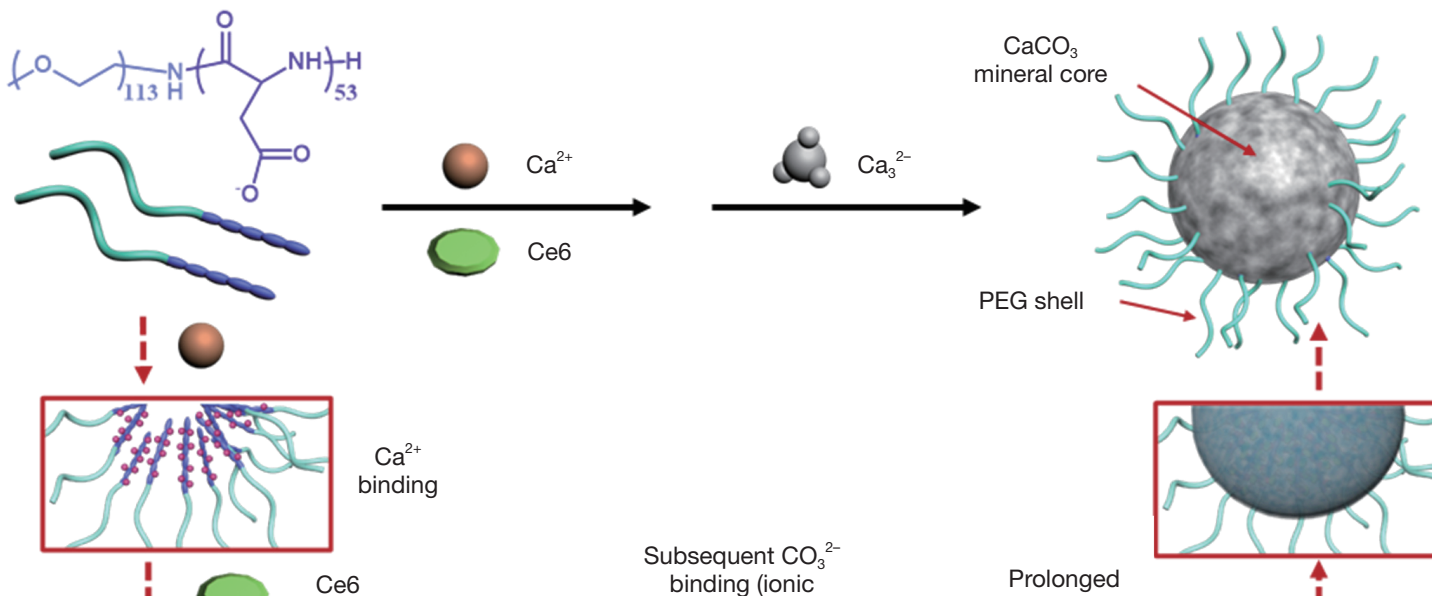

$\mathrm{Ca}^{2+}$
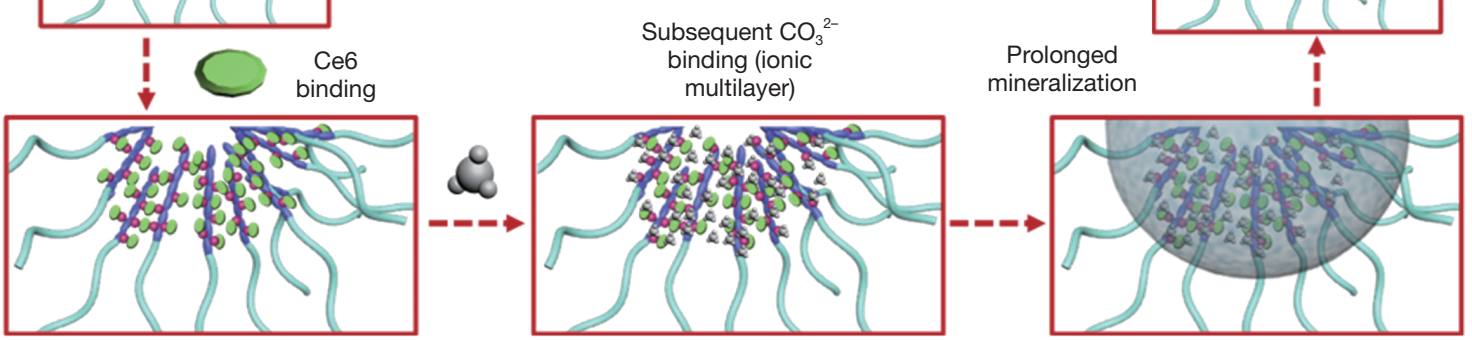

B

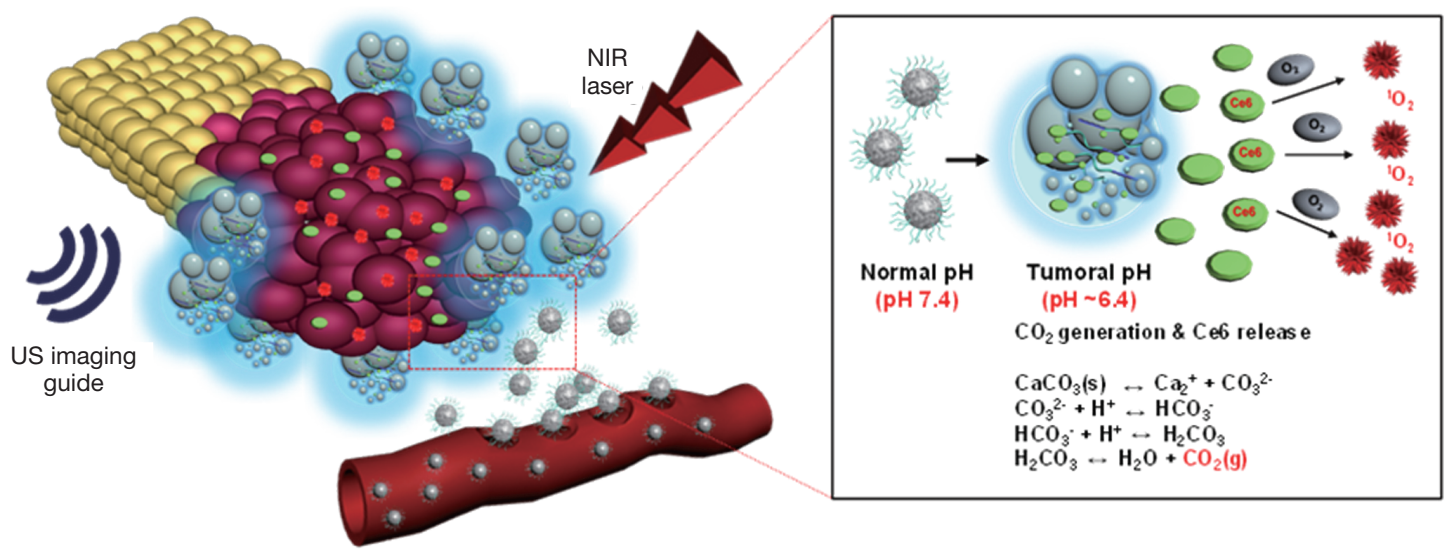

Figure 11 Mineralized bubble-generating theranostic mineralized nanoparticles for US image-guided photodynamic therapy. (A) Fabrication of Ce6-loaded $\mathrm{CaCO}_{3}$-mineralized nanoparticles (Ce6-BMNs); (B) generation of $\mathrm{CO}_{2}$ bubbles with Ce6 release and subsequent PDT upon laser irradiation after tumor accumulation of Ce6-BMNs. Reproduced with permission from (52).

$\mathrm{DOX}-\mathrm{CaCO}_{3}-\mathrm{MNPs}$ suppressed the tumor weight by $85 \%$ compared to the saline-treated group at 16 days after injection.

For successful tumor treatment by photodynamic therapy (PDT), it is of great importance to identify and detect the exact size and location of tumors before laser irradiation to the target site. Furthermore, during the therapy of cancers, real-time monitoring of the therapeutic response is needed (51). To achieve this purpose, US serves as an imaging guidance tool. Park et al. prepared a theranostics system of US imaging and PDT using mineralized hybrid nanocarriers for US image-guided photodynamic therapy (Figure 11) (52). Ce6-loaded bubble-generating mineralized nanoparticles (Ce6-BMNs) were fabricated by a polymeric nanotemplate- $\mathrm{CaCO}_{3}$ mineralization process and provided potential for ultrasound imaging and US image-guided photodynamic therapy in response to a tumoral acidic $\mathrm{pH}$. The Ce6-BMNs showed enhanced structural stability under serum condition. The Ce6-BMNs generated $\mathrm{CO}_{2}$ gas bubbles at tumoral acid $\mathrm{pH}$, which resulted in excellent US 
signals. After NIR laser irradiation of Ce6-BMNs-treated MCF-7 cells, cell viability dramatically decreased. As a result, the Ce6-BMNs exhibited much higher phototoxicity compared with that of the free Ce6-treated group.

\section{Conclusions}

We have introduced the recent research trends of mineralized hybrid nanocarriers system and the understanding of the process of biomimetic mineralization. This mineralization approach plays a vital role in the development of nanocarriers that can prevent the release of drugs and bioactive agents in the blood circulation and can release drugs at the targeted sites. Currently, the mineralized hybrid system is still at a challenging stage of development for biomedical applications, and it continues to have great potential over a wide range of applications and can overcome the disadvantages and limitations of the existence used nanocarriers system.

\section{Acknowledgements}

Funding: SC Lee acknowledges the Bio \& Medical Technology Development Program of the National Research Foundation (NRF) \& a grant by the Korean government (MSIP\&MOHW) (No. 2017M3A9E4048170).

\section{Footnote}

Conflicts of Interest: The authors have no conflicts of interest to declare.

\section{References}

1. Ma L, Liu TW, Wallig MA, Dobrucki IT, Dobrucki LW, Nelson ER, Swanson KS, Smith AM. Efficient Targeting of Adipose Tissue Macrophages in Obesity with Polysaccharide Nanocarriers. ACS Nano 2016;10:6952-62.

2. Chen ZP, Li M, Zhang LJ, He JY, Wu L, Xiao YY, Duan JA, Cai T, Li WD. Mitochondria-targeted drug delivery system for cancer treatment. J Drug Target 2016;24:492-502.

3. Wáng YXJ, Idée JM. A comprehensive literatures update of clinical researches of superparamagnetic resonance iron oxide nanoparticles for magnetic resonance imaging. Quant Imaging Med Surg 2017;7:88

4. Bertrand N, Wu J, Xu X, Kamaly N, Farokhzad OC. Cancer nanotechnology: the impact of passive and active targeting in the era of modern cancer biology. Adv Drug Deliv Rev 2014;66:2-25.
5. Derrick JS, Kerr RA, Nam Y, Oh SB, Lee HJ, Earnest KG, Suh N, Peck KL, Ozbil M, Korshavn KJ, Ramamoorthy A, Prabhakar R, Merino EJ, Shearer J, Lee J-Y, Ruotolo BT, Lim MH. A Redox-Active, Compact Molecule for CrossLinking Amyloidogenic Peptides into Nontoxic, OffPathway Aggregates: In Vitro and In Vivo Efficacy and Molecular Mechanisms. Journal of the American Chemical Society 2015:jacs.5b10043.

6. Yu J, Chu X, Hou Y. Stimuli-responsive cancer therapy based on nanoparticles. Chem Commun (Camb) 2014;50:11614-30.

7. Asanuma D, Takaoka Y, Namiki S, Takikawa K, Kamiya M, Nagano T, Urano Y, Hirose K. Acidic-pH-activatable fluorescence probes for visualizing exocytosis dynamics. Angew Chem Int Ed Engl 2014;53:6085-9.

8. Mi P, Dewi N, Yanagie H, Kokuryo D, Suzuki M, Sakurai Y, Li Y, Aoki I, Ono K, Takahashi H, Cabral H, Nishiyama N, Kataoka K. Hybrid Calcium Phosphate-Polymeric Micelles Incorporating Gadolinium Chelates for ImagingGuided Gadolinium Neutron Capture Tumor Therapy. ACS Nano 2015;9:5913-21.

9. Nomoto T, Fukushima S, Kumagai M, Miyazaki K, Inoue A, Mi P, Maeda Y, Toh K, Matsumoto Y, Morimoto Y. Calcium phosphate-based organic-inorganic hybrid nanocarriers with $\mathrm{pH}$-responsive on/off switch for photodynamic therapy. Biomater Sci 2016;4:826-38.

10. Weiner S, Addadi L. Design strategies in mineralized biological materials. J Mater Chem 1997;7:689-702.

11. Yang Q, Wang S, Fan P, Wang L, Di Y, Lin K, Xiao F-S. $\mathrm{pH}$-responsive carrier system based on carboxylic acid modified mesoporous silica and polyelectrolyte for drug delivery. Chem Mater 2005;17:5999-6003.

12. Choi BY, Park HJ, Hwang SJ, Park JB. Preparation of alginate beads for floating drug delivery system: effects of CO 2 gas-forming agents. Int J Pharm 2002;239:81-91.

13. Pan HB, Darvell B. Calcium phosphate solubility: the need for re-evaluation. Cryst Growth Des 2008;9:639-45.

14. Han MR, Kwon MC, Lee HY, Kim JC, Kim JD, Yoo SK, Sin IS, Kim SM. pH-dependent release property of alginate beads containing calcium carbonate particles. Journal of microencapsulation 2007;24:787-96.

15. Simkiss K, Wilbur KM. Biomineralization: cell biology and mineral deposition. San Diego: Academic Press, 1989.

16. Meyers MA, Lin AY, Seki Y, Chen PY, Kad BK, Bodde S. Structural biological composites: an overview. JOM 2006;58:35-41.

17. Jie Y, Cai Z, Li S, Xie Z, Ma M, Huang X. Hydroxyapatite nucleation and growth on collagen electrospun fibers 
controlled with different mineralization conditions and phosvitin. Macromolecular Research 2017;25:905-12.

18. Hwang SJ, Lee JS, Ryu TK, Kang RH, Jeong KY, Jun DR, Koh JM, Kim SE, Choi SW. Alendronate-modified hydroxyapatite nanoparticles for bone-specific dual delivery of drug and bone mineral. Macromolecular Research 2016;24:623-8.

19. Zimmermann EA, Schaible E, Bale H, Barth HD, Tang SY, Reichert P, Busse B, Alliston T, Ager JW, Ritchie RO. Age-related changes in the plasticity and toughness of human cortical bone at multiple length scales. Proc Natl Acad Sci U S A 2011;108:14416-21.

20. Naka K, Chujo Y. Control of crystal nucleation and growth of calcium carbonate by synthetic substrates. Chem Mater 2001;13:3245-59.

21. Weiner S, Wagner HD. The material bone: structuremechanical function relations. Ann Rev Mater Sci 1998;28:271-98.

22. Schmidt HT, Ostafin AE. Liposome directed growth of calcium phosphate nanoshells. Adv Mater 2002;14:532-5.

23. Schmidt HT, Gray BL, Wingert PA, Ostafin AE. Assembly of aqueous-cored calcium phosphate nanoparticles for drug delivery. Chem Mater 2004;16:4942-7.

24. Xu Q, Tanaka Y, Czernuszka JT. Encapsulation and release of a hydrophobic drug from hydroxyapatite coated liposomes. Biomaterials 2007;28:2687-94.

25. Lammers T, Hennink WE, Storm G. Tumour-targeted nanomedicines: principles and practice. Br J Cancer 2008;99:392-7.

26. Min KH, Kim JH, Bae SM, Shin H, Kim MS, Park S, Lee H, Park RW, Kim IS, Kim K, Kwon IC, Jeong SY, Lee DS. Tumoral acidic pH-responsive MPEG-poly(betaamino ester) polymeric micelles for cancer targeting therapy. J Control Release 2010;144:259-66.

27. Na JH, Lee SY, Lee S, Koo H, Min KH, Jeong SY, Yuk SH, Kim K, Kwon IC. Effect of the stability and deformability of self-assembled glycol chitosan nanoparticles on tumor-targeting efficiency. J Control Release 2012;163:2-9.

28. Lee HJ, Kim SE, Kwon IK, Park C, Kim C, Yang J, Lee SC. Spatially mineralized self-assembled polymeric nanocarriers with enhanced robustness and controlled drug-releasing property. Chem Commun (Camb.) 2010;46:377-9.

29. Min KH, Lee HJ, Kim K, Kwon IC, Jeong SY, Lee SC. The tumor accumulation and therapeutic efficacy of doxorubicin carried in calcium phosphate-reinforced polymer nanoparticles. Biomaterials 2012;33:5788-97.
30. Lee SU, Min KH, Jeong SY, Bae H, Lee SC. Calcium phosphate-reinforced photosensitizer-loaded polymer nanoparticles for photodynamic therapy. Chem Asian J 2013;8:3222-9.

31. Nam HY, Min KH, Choi JR, Lee HJ, Lee SC. Musselinspired poly (L-DOPA)-templated mineralization for calcium phosphate-assembled intracellular nanocarriers. Colloids and Surfaces B: Biointerfaces 2017;157:215-22.

32. Lee H, Dellatore SM, Miller WM, Messersmith PB. Mussel-inspired surface chemistry for multifunctional coatings. Science 2007;318:426-30.

33. Lebedev AV, Ivanova MV, Timoshin AA, Ruuge EK. Effect of group II metal cations on catecholate oxidation. Chem Phys Chem 2007;8:1863-9.

34. Holten-Andersen N, Harrington MJ, Birkedal H, Lee BP, Messersmith PB, Lee KYC, Waite JH. pH-induced metalligand cross-links inspired by mussel yield self-healing polymer networks with near-covalent elastic moduli. Proc Natl Acad Sci U S A 2011;108:2651-5.

35. Koo AN, Min KH, Lee HJ, Jegal JH, Lee JW, Lee SC. Calcium Carbonate Mineralized Nanoparticles as an Intracellular Transporter of Cytochrome c for Cancer Therapy. Chem Asian J 2015;10:2380-7.

36. Zhivotovsky B, Orrenius S, Brustugun OT, Døskeland SO. Injected cytochrome c induces apoptosis. Nature 1998;391:449.

37. Lee HJ, Park DJ, Choi GH, Yang DN, Heo JS, Lee SC. pH-Responsive mineralized nanoparticles as stable nanocarriers for intracellular nitric oxide delivery. Colloids Surf B Biointerfaces 2016;146:1-8.

38. Lu Y, Slomberg DL, Shah A, Schoenfisch MH. Nitric oxide-releasing amphiphilic poly (amidoamine) (PAMAM) dendrimers as antibacterial agents. Biomacromolecules 2013;14:3589-98.

39. Vural KM, Bayazit M. Nitric oxide: implications for vascular and endovascular surgery. Eur J Vasc Endovasc Surg 2001;22:285-93.

40. Huerta S, Chilka S, Bonavida B. Nitric oxide donors: novel cancer therapeutics. Int J Oncol 2008;33:909-27.

41. Ascenzi P, Salvati L, Bolognesi M, Colasanti M, Polticelli F, Venturini G. Inhibition of cysteine protease activity by NO-donors. Curr Protein Pept Sci 2001;2:137-53.

42. Rassaf T, Preik M, Kleinbongard P, Lauer T, Heiß C, Strauer B-E, Feelisch M, Kelm M. Evidence for in vivo transport of bioactive nitric oxide in human plasma. J Clin Invest 2002;109:1241-8.

43. Shin JH, Metzger SK, Schoenfisch MH. Synthesis of nitric oxide-releasing silica nanoparticles. J Am Chem Soc 
2007;129:4612-9.

44. Wang PG, Xian M, Tang X, Wu X, Wen Z, Cai T, Janczuk AJ. Nitric oxide donors: chemical activities and biological applications. Chem Rev 2002;102:1091-134.

45. Mi P, Kokuryo D, Cabral H, Kumagai M, Nomoto T, Aoki I, Terada Y, Kishimura A, Nishiyama N, Kataoka K. Hydrothermally synthesized PEGylated calcium phosphate nanoparticles incorporating Gd-DTPA for contrast enhanced MRI diagnosis of solid tumors. J Control Release 2014;174:63-71.

46. Mi P, Kokuryo D, Cabral H, Wu H, Terada Y, Saga T, Aoki I, Nishiyama N, Kataoka K. A pH-activatable nanoparticle with signal-amplification capabilities for noninvasive imaging of tumour malignancy. Nat Nanotechnol 2016;11:724-30.

47. Helmlinger G, Yuan F, Dellian M, Jain RK. Interstitial pH and $\mathrm{pO} 2$ gradients in solid tumors in vivo: high-resolution measurements reveal a lack of correlation. Nat Med 1997;3:177.

Cite this article as: Min KH, Lee HJ, Lee SC, Park K. Biomineralized hybrid nanoparticles for imaging and therapy of cancers. Quant Imaging Med Surg 2018;8(7):694-708. doi: 10.21037/qims.2018.08.04
48. Chen G, Qiu H, Prasad PN, Chen X. Upconversion Nanoparticles: Design, Nanochemistry, and Applications in Theranostics. Chem Rev 2014;114:5161-214.

49. Ryu JH, Son S, Kim YS, Kim SH, Leary JF, Choi K, Kwon IC. Theranostic nanoparticles for future personalized medicine. J Control Release 2014;190:477-84.

50. Min KH, Min HS, Lee HJ, Park DJ, Yhee JY, Kim K, Kwon IC, Jeong SY, Silvestre OF, Chen X. pH-controlled gas-generating mineralized nanoparticles: a theranostic agent for ultrasound imaging and therapy of cancers. ACS Nano 2015;9:134-45.

51. Zhu M, Sun Z, Ng CK. Image-guided thermal ablation with MR-based thermometry. Quant Imaging Med Surg 2017;7:356.

52. Park DJ, Min KH, Lee HJ, Kim K, Kwon IC, Jeong SY, Lee SC. Photosensitizer-loaded bubble-generating mineralized nanoparticles for ultrasound imaging and photodynamic therapy. J Mater Chem B 2016;4:1219-27. 